\title{
TOWARD A CFD-GRADE DATABASE ADDRESSING LWR CONTAINMENT PHENOMENA
}

\author{
Domenico Paladino ${ }^{1}$, Michele Andreani, Robert Zboray and Jörg Dreier
}

\author{
Laboratory for Thermal-Hydraulics \\ Nuclear Energy and Safety Department \\ PAUL SCHERRER INSTITUT \\ CH-5232 Villigen PSI
}

\begin{abstract}
The large-scale, multi-compartment PANDA facility (located at PSI in Switzerland) is one of the stateof-the-art facilities which is continuously upgraded to progressively match the requirements of CFD-grade experiments. Within the OECD/SETH projects, the PANDA facility has been used for the creation of an experimental database on basic containment phenomena e.g. gas mixing, transport, stratification, condensation. In the PANDA tests, these phenomena are driven by large scale plumes or jets. In the paper a selection of the SETH PANDA experimental results is presented. Examples of analytical activities performed at PSI using the GOTHIC, CFX-4 and CFX-5 codes will be used to illustrate how the spatial and temporal resolutions for the measurement grid in PANDA tests are adequate for CFD code assessment and validation purposes.
\end{abstract}

\section{INTRODUCTION}

The general need for a new generation of thermal-hydraulic codes based on advanced multidimensional/multi-fluid models has been identified by several international expert groups (OECD, 2000) and stressed in several workshops and conferences. These new codes are needed to address new safety issues, re-assess the safety of certain reactor types (e.g., Eastern reactors), to support optimization in the design of future reactors, and more precisely quantify certain phenomena in order to remove excessive conservatism.

A three-dimensional description of certain processes is specially needed for both primary side and containment, requiring the coupling of traditional, lumped-parameter or 1D representations of most of the system with detailed, CFD-like treatment of certain parts. These enhanced computational tools can take advantage of the continuing and rapid increase in computing capability, accumulated knowledge in understanding thermal-hydraulic phenomena, and progress in numerical techniques. One of the hindrances to the development of these new tools is the lack of an adequate experimental data base for the validation of the new capabilities. An important aspect of the new experiments that has also been emphasized is the need to obtain data on large-scale tests to reduce the impact of scaling distortions in the assessment of the code models. These and other aspects of the current development of the new computational tools for reactor safety have been addressed by Yadigaroglu et al. (2003). Gas transport and mixing in the containment are considered high ranking phenomena which concern nuclear safety (Smith, 2009). The phenomena are driven by buoyant high-momentum injections (jets) and/or low momentum injection (plumes), depending on the transient scenario and break location. For instance, mixing in the immediate vicinity of the postulated break is clearly initially dominated by very high velocity efflux. Plumes with moderate velocity efflux can be generated in a number of circumstances: for instance, in the break compartment during the long-term pressurization phase, or in any of the apertures between two compartments, if the mass flows are sufficiently high and/or the density differences between efflux and ambient are sufficiently low. On the other hand, low-momentum flows are responsible for most of the transport processes within the containment. With respect to low-momentum flows, phenomena of interest include free plumes (as produced by the efflux from the break compartment in a larger room or directly from a break flow), wall plumes (such those produced by low mass flows through inter-compartment apertures), and propagating stratification fronts in the ambient (for any kind of stably stratified

${ }^{1}$ Corresponding author: Tel: + 41-56-3104373; Fax: + 41-56-3104481; E-mail: domenico.paladino@psi.ch 
conditions). In general there is considerable interest by the scientific community for these type of flows. The data base available in the literature for flow of steam in air is rather sparse, and many tests include additional effects, such as condensation on walls.

The PANDA part of the OECD-SETH project has been carried out with one of main goals being to generate an experimental database on the phenomena of gas mixing and stratification induced by plumes or jets. The SETH PANDA tests include three series of tests named Wall plume (Auban et al. 2007, Paladino et al. 2010), Free plume (Zboray et al. 2006), Horizontal jets (Paladino et al. 2007). In addition, a Three-gas mixture test has been performed (Paladino et al. 2010). The analytical activities were performed with CFD codes and with advanced Lumped Parameter codes. These analytical activities provided a contribution toward the assessment of strengths and drawbacks of different codes in analyzing the phenomena occurring in these PANDA tests (OECD 2007; Royl et al. 2008, 2009; Andreani et al. 2008, 2010a, Bentaib et al. 2009, Andreani and Paladino 2010). A number of simulation challenges were identified in relation to: gas transport and stratification for the case of high flow exit elevations; prediction of peak gas temperature (mainly in the near-wall plume test series); stratification disruption and erosion for the case of the three gas test; and condensation/condensate transport and re-evaporation phenomena.

In the present paper, we present a selection of the experimental results, illustrating the effects of parametric variation of the PANDA test conditions in the various series on the evolution of the basic physical phenomena. Also, a few examples of test simulations performed at PSI with GOTHIC and CFX codes are included in the paper to show how the data could be used for the assessment of advanced 3D codes.

\section{PANDA FACLITY}

PANDA is a large-scale, thermal-hydraulics test facility designed and used for investigating containment system behavior and related phenomena for different ALWR designs, and for large-scale separate effect tests (Dreier et al., 2008). The facility was used to study the passive decay heat removal systems and containment response of the Simplified Boiling Water Reactor (SBWR) and the Economic Simplified Boiling Water Reactor (ESBWR) designs from General Electric (GE), as well as of the SWR1000 design from Siemens-KWU (now AREVA) in the case of accident transients. Other studies were carried out on natural-circulation flow and stability in the Reactor Pressure Vessel (RPV) of advanced BWRs.

The PANDA facility has a modular structure, consisting of six cylindrical pressure vessels and four water pools containing four condensers. In the studies related to the ESBWR, the vessels were representing: the Reactor Pressure Vessel, RPV (one vessel), the Drywell, DW (two vessels), the Suppression Chamber, SC (two vessels) and the Gravity Driven Cooling System, GDCS (one vessel). The pools and condensers represented the three Passive Containment Cooling Condensers (PCCs) and the Isolation Condenser (IC) (Figure 1). The total volume of the six vessels is about $460 \mathrm{~m}^{3}$, and the total height of the facility is $25 \mathrm{~m}$. The maximum operating conditions are 10 bar pressure and $200{ }^{\circ} \mathrm{C}$. In the RPV, electrical heaters are installed with a maximum power of $1.5 \mathrm{MW}$, providing the steam injected into the vessels during a SETH test. The facility is equipped with auxiliary systems which allow injection into the vessels of air, steam, helium and water. These systems are regularly used to precondition the facility to the specified test conditions. The control system allows all the main operations needed for preconditioning the facility and for performing a test from a control room. Two PANDA vessels (Drywell 1 and Drywell 2 in Figure 1) are used in the SETH project to represent nuclear containment compartments. These two vessels, having each a diameter of about $4 \mathrm{~m}$ and height of $8 \mathrm{~m}$ (the total volume of the two vessels being about $183 \mathrm{~m}^{3}$ ), are interconnected by a pipe (IP) of about $1 \mathrm{~m}$ diameter.

For the SETH tests, it was necessary to upgrade the auxiliary systems. This included the implementation of components for reaching the specified vessel wall temperature, and the fluid temperature and composition. Also, additional components have been included for obtaining the specified injection fluid flow rate, temperature and composition and components to control the fluid pressure by regulating the venting flow rate.

The PANDA instrumentation ${ }^{2}$ allows for the measurement of fluid and wall temperatures, absolute and differential pressures, flow rates, heater power, gas concentrations and flow velocities. The sensors are implemented in all the compartments of the facility, in the system lines, and in the auxiliary systems. For

${ }^{2}$ The description of PANDA instrumentation is related to the configurations used for the SETH tests. Later in the on-going SETH-2 project, the PANDA instrumentation has been further upgraded by increasing the number of sensors for temperature and gas concentration measurements, and with the installation of novel sensors for measuring low velocity flows (i.e. $0.05-0.15 \mathrm{~m} / \mathrm{s}$, a typical range for the IP). 
the SETH tests, the measurement grids in DW1 and DW2 have been refined in consideration of the spatial resolution required in each test, in order to obtain experimental data with a spatial resolution suitable for advanced code validation. Scoping calculations performed at PSI using GOTHIC assisted in the identification of optimal locations, and where to place the sensors.

Temperature measurements: up to 339 K-type thermocouples (TCs) were used for measuring fluid temperatures, and the inside and outside wall temperatures of DW1, DW2 and the IP with an accuracy of around $0.5^{\circ} \mathrm{C}$. Temperature sensors are installed in the vessels at different heights: identified as Level A (near the top of the vessels) to Level $\mathrm{T}$ (near the bottom of the vessel), and at different angles and radial distances from the vessel axis.

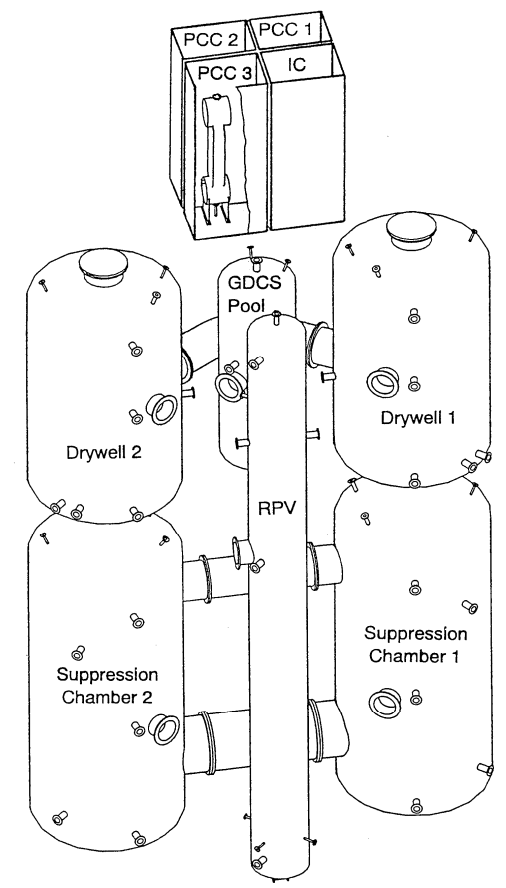

Figure 1: Schematic of PANDA vessels and pools

Concentration measurements: up to 47 sampling lines (24 capillary tubes in DW1, 18 in DW2 and 5 in the IP), connected to a Mass Spectrometer (MS), are available for gas concentration measurements. The system can measure the full range of gas concentration and composition. The gas mixtures used for the SETH tests are either: steam/air, steam/helium or steam/air/helium. The number of sampling lines used for measurements in each test was 38. A thermocouple is placed close (a few millimeters) from each gas sampling port, so that gas concentration and temperature measurements are available at the same spatial location $^{3}$. For steam/air mixtures, the absolute error on the measured steam/air molar fraction is lower than $+/-1.5 \%$.

Injection and venting flow rates: are measured with vortex flow meters with an accuracy of $\sim 1.1 \%$.

Measurement of $1 D$ velocities: 3 vane wheel sensors were used to measure the vertical component of the flow velocity at three different heights in DW1. The accuracy of the vane wheel sensors is about $1 \%$ of the measured value. The 3 sensors were installed above the injection location at different elevations.

Measurement of 2D velocity fields: a commercial Particle Image Velocimetry (PIV) set-up is used to measure 2D velocity fields in DW1 in a vertical plane aligned with the vertical mid-plane of the injection pipe. Olive oil, dispersed into small particles by a spray nozzle, is used to provide seeding particles for the PIV technique. The oil particles are injected into the steam flow directed into DW1. The PIV system provides 2D instantaneous velocity fields at a sampling rate of $4 \mathrm{~Hz}$.

\section{SETH PANDA TEST MATRIX}

\subsection{Wall plume tests}

\footnotetext{
${ }^{3}$ Saturation temperatures can be obtained by measuring steam partial pressure (by the molar fraction measurements) and using steam tables, in this way it is possible to assess if steam is superheated, and thereby to estimate the timing of the start of the condensation process (D. Paladino et al. 2010a).
} 
Figure 2 and Table 1 show the configurations and conditions for the wall plume test series. As the new experiments provided data for a thorough assessment of the capabilities of the codes, tests with low elevation injection were considered to check that a modeling strategy valid for high injection can still provide good results for other cases. In addition to the specific aims above, the test series addresses the issues of stratification-front propagation and the effect of perturbations on the flow structure and mixing. As one of the main effects on the gas distribution is the elevation of the injection, tests are carried out for three different injection elevations. The $\mathrm{L}$ in Tables 1 to 5 indicates the elevation of the injection line exit with respect to the bottom of DW1 (i.e. $1.8 \mathrm{~m}, 4 \mathrm{~m}$ and $6 \mathrm{~m}$ ). It is worth recalling that stratification is controlled by the rate of entrainment into the buoyant jet. Tests on wall plumes relevant to the containment response must be carried out with geometrical configurations in which the ratio $H / D$ is in the range of the interesting phenomena (height $H$ and initial diameter $D$ of the plume). As the transport processes in the containment have a length scale from a few meters (a compartment) to several tens of meters (a large, dry containment), and typical wall plume source diameters are less than one meter, the ratio $H / D$ spans a range from a few units to about 100 . For the reference diameter of about $0.16 \mathrm{~m}$ chosen for the tests, the selected elevations lead to $H / D$ ratios between 10 and 35 . Fluid injection velocity was in the range 1 to $5 \mathrm{~m} / \mathrm{s}$ (as well the Froude number). The injected steam is always superheated with respect to the fluid and vessel wall temperatures, and only in test $9 \mathrm{bis}^{4}$ could condensation take place during the transient. The initial fluid composition in the DW vessels was $50 \%$ molar fraction of air $\left(\mathrm{X}_{\text {air }}\right)$ in Test 11, and in all the other tests was $100 \%$ air.

Table 2: Test matrix for near-wall plume tests

\begin{tabular}{|c|c|c|c|c|c|c|c|c|}
\hline Test & $\begin{array}{c}\mathrm{L} \\
(\mathrm{m})\end{array}$ & $\begin{array}{c}\mathrm{V} \\
(\mathrm{m} / \mathrm{s})\end{array}$ & $\begin{array}{c}\mathrm{T}_{\mathrm{i}} \\
(\mathrm{C})\end{array}$ & $\begin{array}{c}\mathrm{T}_{\mathrm{w}} \\
\left({ }^{\circ} \mathrm{C}\right)\end{array}$ & $\begin{array}{c}\mathrm{X}_{\text {air }} \\
(\%)\end{array}$ & $\mathrm{Fr}_{0}$ & Vent & Note/studied effect \\
\hline 9 & 1.8 & 1 & 140 & 108 & 100 & 1 & V2T & Reference Test \\
\hline $9 \mathrm{bis}$ & 1.8 & 1 & 108 & 76 & 100 & 1 & $\mathrm{~V} 2 \mathrm{~T}$ & Condensation \\
\hline 10 & 1.8 & 1 & 140 & 108 & 100 & 1 & $\mathrm{~V} 1 \mathrm{~B}$ & Vent location \\
\hline 11 & 1.8 & 1 & 140 & 108 & 50 & 1.5 & $\mathrm{~V} 2 \mathrm{~T}$ & Composition \\
\hline 12 & 4 & 1 & 140 & 108 & 100 & 1 & $\mathrm{~V} 2 \mathrm{~T}$ & Injection elevation \\
\hline 13 & 4 & 1 & 140 & 108 & 100 & 1 & $\mathrm{~V} 1 \mathrm{~B}$ & Vent location \\
\hline 14 & 6 & 1 & 140 & 108 & 100 & 1 & $\mathrm{~V} 2 \mathrm{~T}$ & Stratification \\
\hline 16 & 1.8 & 3 & 140 & 108 & 100 & 3 & $\mathrm{~V} 2 \mathrm{~T}$ & $\mathrm{Fr}_{0}$ on jet trajectory \\
\hline 17 & 1.8 & 5 & 140 & 108 & 100 & 5 & $\mathrm{~V} 2 \mathrm{~T}$ & Same as for Test 16 \\
\hline
\end{tabular}

Tests 9, 9bis, 11, 16, 17

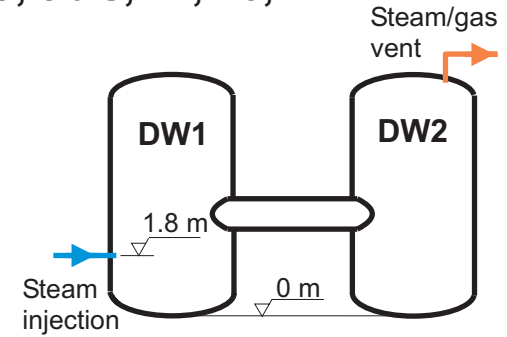

Test 10

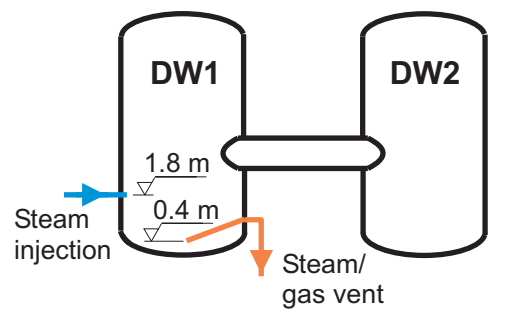

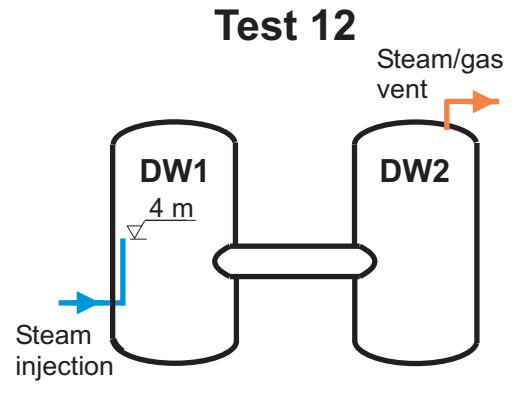

Test 13

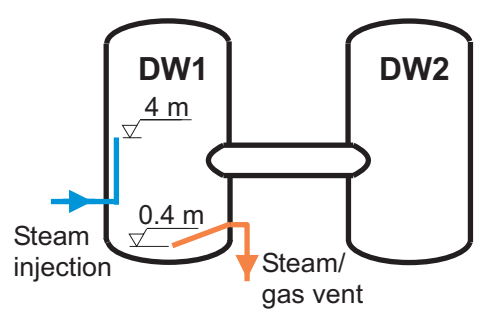

Test 14

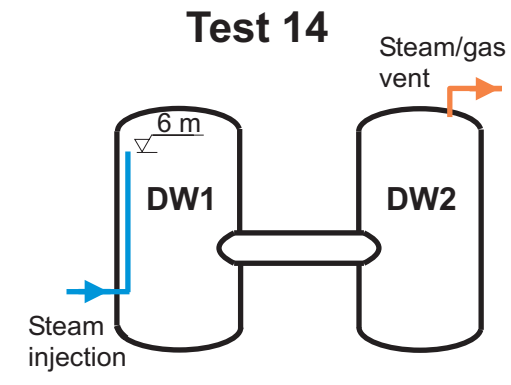

${ }^{4}$ The term "bis" added at the after a test number indicate that the test is with condensation. Therefore Test 9bis has similar geometrical and initial and boundary conditions as to Test 9 , but the fluid injection and vessel temperature are such that condensation takes place during the transient. Similar considerations are valid for Test 21 bis with respect to Test 21 (Table 2) and Test 4 bis with respect to Test 4 (Table 3 ). Test 25 (Table 5) has been defined according other considerations and is also with condensation. 
Figure 2: wall plume tests

The wall plume tests were performed at constant pressure. Therefore, continuous venting was taking place during the test, either via the top of DW2 (V2T) or the bottom of DW1 (V1B). The last column of Table 2 gives some notes concerning the individual test, or the main effect investigated.

\subsection{Free plume tests}

The definition of the test matrix has a rationale similar to that discussed for wall plume tests. Performing tests with free plumes for the same range of parameters used for the wall plumes, a consistent data base for assessing modeling strategies for both types of flows has been provided. The configurations and test conditions for the free plume tests are shown in Table 2 and Figure 3. The test parameters were chosen similar to those for the wall plume tests to investigate the effect of the vicinity of a wall on the plume structure and consequent mixing. The inner diameter of the injection was fixed at $0.15 \mathrm{~m}$, and for this size the same kind of scaling considerations used for the wall plumes (based on using reasonable values for the ratio $H / D$ ) apply also to the free plumes. To limit the number of tests, only two elevations were investigated. Velocities and concentrations are again chosen in a way to produce values of the Froude number close to unity, or slightly greater. The test 21 bis was the only test of the series where condensation took place.

The free plume tests were performed at constant pressure, so continuous venting was taking place during the test, either via by V2T or V1B.

Table 2: Test matrix for free plume tests

\begin{tabular}{|c|c|c|c|c|c|c|c|l|}
\hline Test & $\begin{array}{c}\mathrm{L} \\
(\mathrm{m})\end{array}$ & $\begin{array}{c}\mathrm{V} \\
(\mathrm{m} / \mathrm{s})\end{array}$ & $\begin{array}{c}\mathrm{T}_{\mathrm{i}} \\
\left({ }^{\circ} \mathrm{C}\right)\end{array}$ & $\begin{array}{c}\mathrm{T}_{\mathrm{w}} \\
\left({ }^{\circ} \mathrm{C}\right)\end{array}$ & $\begin{array}{c}\mathrm{X}_{\text {air }} \\
(\%)\end{array}$ & $\mathrm{Fr}_{0}$ & Vent & $\begin{array}{c}\text { Note/studied } \\
\text { effect }\end{array}$ \\
\hline 18 & 2 & 1 & 140 & 108 & 100 & 1 & V2T & Reference test \\
\hline 19 & 2 & 1 & 140 & 108 & 14 & 2.6 & V2T & Composition \\
\hline 20 & 2 & 1 & 140 & 108 & 100 & 1 & V1B & Vent location \\
\hline 21 & 6 & 1 & 140 & 108 & 100 & 1 & V2T & Injection Elev. \\
\hline $21 \mathrm{bis}$ & 6 & 1 & 108 & 76 & 100 & 1 & V2T & Condensation \\
\hline 22 & 6 & 1 & 140 & 108 & 14 & 2.6 & V2T & Composition \\
\hline
\end{tabular}

\subsection{Horizontal jet tests}

One of the main effects of buoyant, horizontal, impinging jets on the distribution of a second species in the containment atmosphere is their ability to destabilize the stratification below the elevation of the injection. On the contrary, above the level of the injection the fluid is well mixed. The mixing of fluid below the injection will influence the distribution of gases within the containment, and, under certain conditions, will also affect the total pressure. Two sets of experiments were carried out. The test specifications are shown in Tables 3 and 4 and illustration in Figure 4. The horizontal jet tests were performed at constant pressure, therefore continuous venting was taking place during the test, either via V2T or V1B.

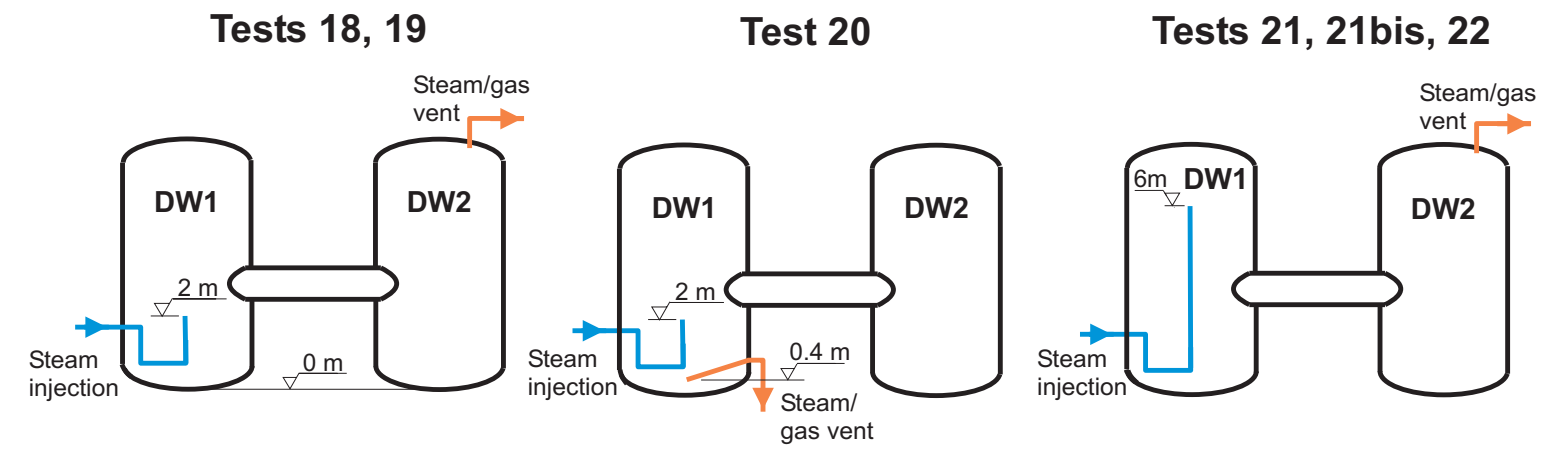

Test 20

Tests 21, 21bis, 22

Figure 3: free plume tests 
Table 3: Test matrix for horizontal jet tests with steam injection

\begin{tabular}{|c|c|c|c|c|c|c|c|c|c|}
\hline Test & $\begin{array}{c}\mathrm{L} \\
(\mathrm{m})\end{array}$ & $\begin{array}{c}\mathrm{V} \\
(\mathrm{m} / \mathrm{s})\end{array}$ & $\begin{array}{c}\mathrm{T}_{\mathrm{i}} \\
\left({ }^{\circ} \mathrm{C}\right)\end{array}$ & $\begin{array}{c}\mathrm{T}_{\mathrm{w}} \\
\left({ }^{\circ} \mathrm{C}\right)\end{array}$ & $\begin{array}{c}\mathrm{X}_{\mathrm{air}} \\
(\%)\end{array}$ & $\mathrm{Fr}_{0}$ & $\mathrm{Re}_{0}$ & Vent & Note/effect \\
\hline 1 & 4 & 15 & 140 & 108 & 20 & 36 & $6.7 \mathrm{E} 5$ & $\mathrm{~V} 2 \mathrm{~T}$ & Reference test \\
\hline 2 & 2 & 7 & 140 & 108 & 20 & 17 & $3.1 \mathrm{E} 5$ & $\mathrm{~V} 2 \mathrm{~T}$ & Jet velocity \\
\hline 4 & 2 & 12.5 & 140 & 108 & 100 & 17 & $5.6 \mathrm{E} 5$ & $\mathrm{~V} 2 \mathrm{~T}$ & Jet velocity \\
\hline 4 bis & 2 & 12.5 & 108 & 76 & 100 & 18 & $6.3 \mathrm{E} 5$ & V2T & Condensation \\
\hline
\end{tabular}

Table 4: Test matrix for horizontal jet tests with steam/helium injection

\begin{tabular}{|c|c|c|c|c|c|c|c|c|c|}
\hline Test & $\begin{array}{c}\mathrm{L} \\
(\mathrm{m})\end{array}$ & $\begin{array}{c}\mathrm{V} \\
(\mathrm{m} / \mathrm{s})\end{array}$ & $\begin{array}{c}\mathrm{T} \\
\left({ }^{\circ} \mathrm{C}\right)\end{array}$ & $\begin{array}{c}\mathrm{X}_{\text {helium }}(\%) \\
(\%\end{array}$ & $\begin{array}{c}\mathrm{T}_{\mathrm{w}} \\
\left({ }^{\circ} \mathrm{C}\right)\end{array}$ & $\mathrm{Fr}_{0}$ & $\mathrm{Re}_{0}$ & $\mathrm{~V}$ & Note/effect \\
\hline 5 & 4 & 20 & 140 & 30 & 108 & 35 & $6.8 \mathrm{E} 5$ & $\mathrm{~V} 2 \mathrm{~T}$ & Reference test \\
\hline 6 & 2 & 9.5 & 140 & 30 & 108 & 17 & $3.2 \mathrm{E} 5$ & V2T & Jet velocity \\
\hline 7 & 4 & 20 & 140 & 30 & 108 & 35 & $6.8 \mathrm{E} 5$ & V1B & Vent location \\
\hline 8 & 2 & 12.5 & 140 & 47 & 108 & 17 & $3.5 \mathrm{E} 5$ & V2T & Jet velocity \\
\hline \multicolumn{2}{|l|}{ DWs initially filled with pure steam }
\end{tabular}

Tests 2, 4, 4bis, 6, 8

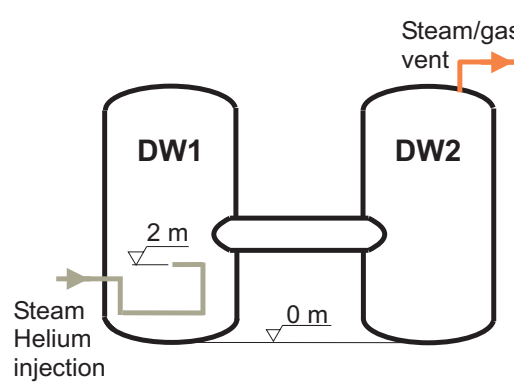

Tests 1, 5

Test 7

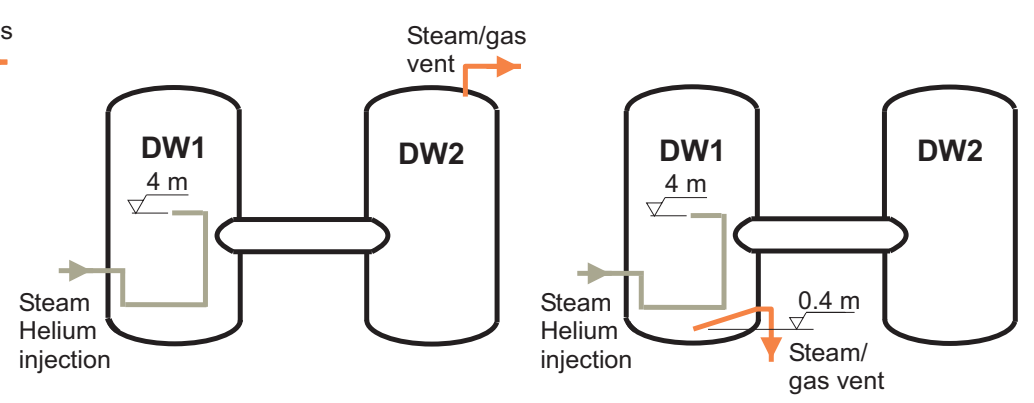

Figure 4: horizontal jet tests

In the first set of tests, steam is injected in the DW1 vessel initially filled with air, or a mixture of steam and air. In the second set, the hydrogen issue is addressed by injecting a mixture of helium and steam into the DW1 vessel initially filled with steam. The fluid injected was superheated to produce temperature differences in both vessels sufficiently high to be detected. One test with condensation was carried out (Test 4bis). The initial fluid and wall temperatures are substantially lower than the prevailing saturation temperature, and the injected fluid is saturated. The temperature difference between the injected fluid and initial ambient temperature was the same as for the reference case without condensation. The test with injection at low elevation and initially pure air conditions were chosen, since the jet-to-wall impact velocities and the concentration gradients are large, and so the condensation rate can also be expected to be large.

\subsection{Three-gas mixture tests}

One SETH PANDA test has been performed with a three-gas mixture, simulating conditions closer to those occurring in the reactor containment. In fact, any safety-relevant condition for the evaluation of a severe accident scenario implies the condensation of steam on the containment structures, with its effects on the separation and stratification of hydrogen. To increase the thermal energy storage capability of the structures, and to enhance condensation effects, the pressure during this test was allowed to increase. Instead of venting into the atmosphere, the WW1 and WW2 vessels (combined volume: $241 \mathrm{~m}^{3}$ ) and the 
GDCS $^{5}$ (volume: $17.6 \mathrm{~m}^{3}$ ) were used as buffer volumes. The conditions and configuration for the threegas mixture test are shown in Table 5 and Figure 5.

Table 5: Parameters for the three-gas mixture test 25

\begin{tabular}{|c|c|c|c|c|c|c|c|c|c|}
\hline $\begin{array}{c}\text { Test } \\
\text { No. } 25 \\
\text { Phase }\end{array}$ & $\begin{array}{l}\mathrm{L} \\
(\mathrm{m})\end{array}$ & $\begin{array}{c}\mathrm{V} \\
(\mathrm{m} / \mathrm{s})\end{array}$ & $\begin{array}{c}\mathrm{T}_{\mathrm{i}} \\
\left({ }^{\circ} \mathrm{C}\right)\end{array}$ & $\begin{array}{l}X_{\mathrm{He}} \\
(\%)\end{array}$ & $\begin{array}{l}\mathrm{T}_{\mathrm{w}} \\
\left({ }^{\circ} \mathrm{C}\right)\end{array}$ & $\begin{array}{l}X_{\text {air }} \\
(\%)\end{array}$ & $\mathrm{Fr}_{0}$ & $\mathrm{~V}$ & Notes \\
\hline 1 & 4 & 4.3 & 120 & 36 & 27 & 100 & 2.3 & \multirow{2}{*}{$\begin{array}{l}\mathrm{V} 1 \mathrm{~B} \\
\text { (vent } \\
\text { to } \\
\text { WW1) }\end{array}$} & $\begin{array}{l}\text { Steam/helium } \\
\text { injection } \\
\text { phase }\end{array}$ \\
\hline 2 & 4 & 1.6 & 150 & 0 & $*$ & $*$ & $*$ & & $\begin{array}{l}\text { Steam } \\
\text { injection }\end{array}$ \\
\hline \multicolumn{10}{|c|}{ Initial pressure: $0.13 \mathrm{MPa}$ (will increase during test) } \\
\hline
\end{tabular}
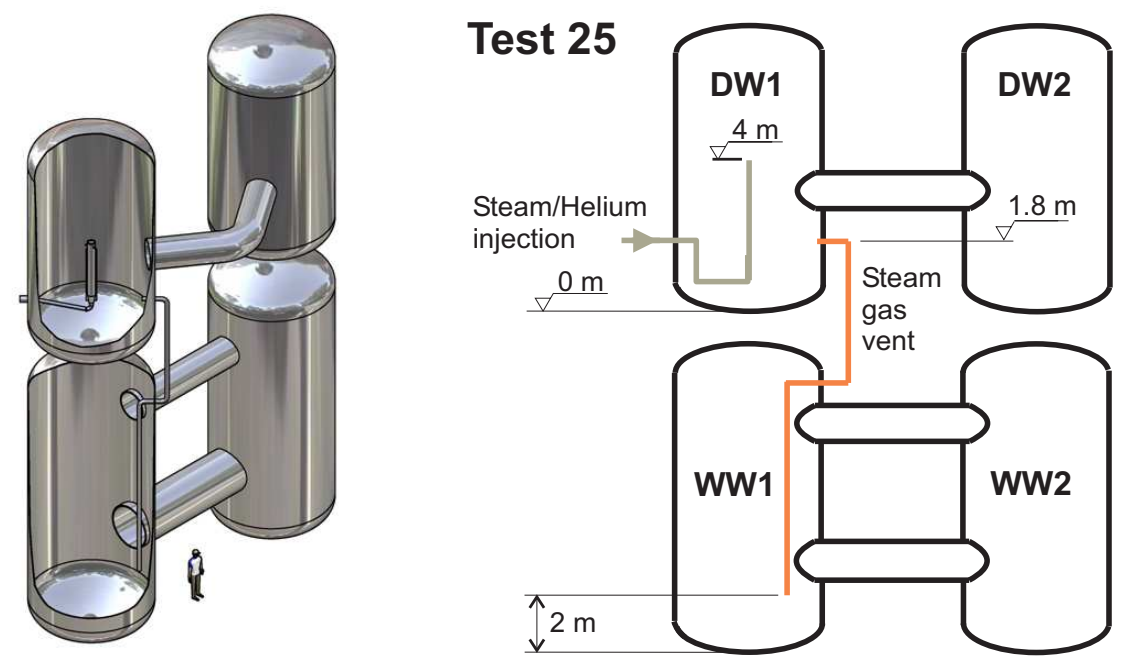

Figure 5: three-gas mixture test

The exit diameter of the injection line was $0.2 \mathrm{~m}$, and the elevation was $4 \mathrm{~m}$ above the bottom of Vessel 1 . The test consisted of two phases of 2 hours each. In Phase 1, a mixture of helium and steam was injected into the vessels (DW1 and DW2) both initially filled with air. The mixture injection temperature was 120 ${ }^{\circ} \mathrm{C}$, and the exit velocity $4.3 \mathrm{~m} / \mathrm{s}$. The corresponding initial Froude number was $\mathrm{Fr}_{\mathrm{o}} \sim 2.3$. In Phase 2, only steam at $150{ }^{\circ} \mathrm{C}$ was injected with an exit velocity of $1.6 \mathrm{~m} / \mathrm{s}$.

\section{PANDA TEST RESULTS}

The aim in this section is to provide a short overview of the SETH PANDA tests, and some examples of the use of the data for the assessment of the GOTHIC and CFX-4 and CFX-5 codes. More detailed presentations of the experimental results are reported for the near wall plume tests by Auban et al. (2007), and Paladino et al. 2010a, for the free plumes by Zboray and Paladino (2010), for the horizontal jet series by Paladino et al. (2010b), and for the Three-gas mixture test by Paladino et al. (2010c). A detailed analysis of the PANDA SETH tests, carried out at PSI using GOTHIC, is reported by Andreani et al. (2010), and Andreani and Paladino (2010).

Concerning the use of the test data for the assessment of CFD codes, some of the most important features of the experiments in PANDA addressed in this paper are:

- Specified test initial and boundary conditions;

- Test repeatability;

\footnotetext{
${ }^{5}$ The GDCS vessel is not shown in Figure 5. This compartment was connected during the test 25 to the WW through pipe lines
} 
- Characterization of gas stratification build-up;

- Characterization of plume trajectory and flow pattern (for the near-wall plume tests);

- Characterization of flow velocity (2D with PIV).

Other phenomena also assessed in PANDA tests, but these will not be discussed (for sake of brevity) in the present paper are for example:

- Flow transport in the DW-IP;

- Characterization of the jet impinging locations (for the horizontal jet tests);

- Characterization of the effect of condensation;

- Flow reversal in the DW-IP;

- Characteristics of the plume trajectory rising from DW-IP into DW2;

- Changing from positive to negative buoyant plume in the three-gases test (fountain effect);

- Helium double stratification in the three-gases test (i.e. in the upper and lower region of DW2);

- Effect of perturbations induced by the inter-compartment flow in the DW-IP on the plume trajectory evolution;

- Plume acceleration due to the buoyancy variation.

\subsection{Initial and boundary conditions}

For code validation purposes, it was important to obtain during the preconditioning phase of the facility, and during the test, well-controlled initial and boundary conditions. In Figure 6, as an example, are shown the initial and boundary conditions for Test 12 (the other PANDA tests have similar mean values and standard deviations for the specified parameters). A typical test duration was 2 hours. Figure 6 (a) shows the vertical temperature profiles in the wall and in the fluid $(11700 \mathrm{~mm}$ is the elevation corresponding to the bottom of the DW vessels, and $19700 \mathrm{~mm}$ is the elevation corresponding to the top of the DW vessels, (i.e. the DW vessels are elevated with respect to the floor of the PANDA building), averaged over the $60 \mathrm{~s}$ before the start of the test. The temperatures in the IP were in each test slightly lower as a consequence of its slightly smaller wall thickness, and slightly higher associated heat losses.

Figures 6 (b), 6 (c) and 6 (d) show the test conditions for the fluid injection temperature, vessel pressure and fluid injection flow rate. The captions show the nominal values, the mean values and the standard deviations. In the SETH PANDA tests it was always possible to obtain initial and boundary conditions very chose to the specified nominal values.

\subsection{Test repeatability}

All the PANDA tests were performed following well-defined test procedures, which enabled re-producible test initial and boundary conditions. Test repeatability was assessed by repeating a few tests two or three times. Figure 7 shows the gas concentration at different times over the vertical central axis of DW1 (a) and DW2 (b) for Test 16-1 and the second run (i.e. repetition test) Test 16-2. Considering the large scale of PANDA facility and the complexity associated with the facility preconditioning and test performance (e.g. heating up, pressurizing, reaching the specified mixture composition, injection conditions, etc.) a very good level of test repeatability was obtained.

As it has been pointed out (footnote 1) each test with condensation was performed with similar conditions with respect to the parallel test without condensation: namely Test 4bis and Test 4 (Table 4); Test 9bis and Test 9 (Table 2); Test 21 bis and Test 21 (Table 3). It can be mentioned that Test 9 and Test 9bis (Paladino et al 2010a) show identical phenomena behavior before the start of condensation; this is also important information on test repeatability.

\subsection{Characterization of gas stratification build-up}

Gas stratification build-up was a function of several parameters: e.g. initial Froude number, injection and vent location, initial gas composition and condensation. Figure 7 related to Test 16, i.e. near-wall plume with lower elevation injection (1.8 m above drywell bottom (a.d.b.)) for intermediate and low flow rates. A strong gas stratification formed in both DW vessels. The key elevations marking a sharp change in concentration are the injection elevation in DW1 and the elevation of the IP in DW2. It is possible to see that well-mixed conditions are reached above the injection location, but below this the fluid remains 
stratified. Similar stratification build-up was obtained for the other tests at different radial locations or elevations, and at different Froude numbers.

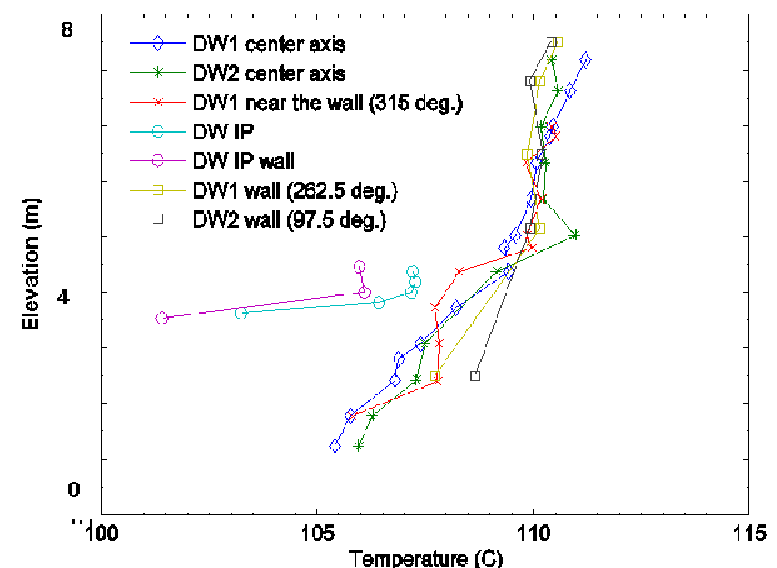

(a) Fluid and wall temperatures $\left({ }^{\circ} \mathrm{C}\right)$ Nominal value: 108

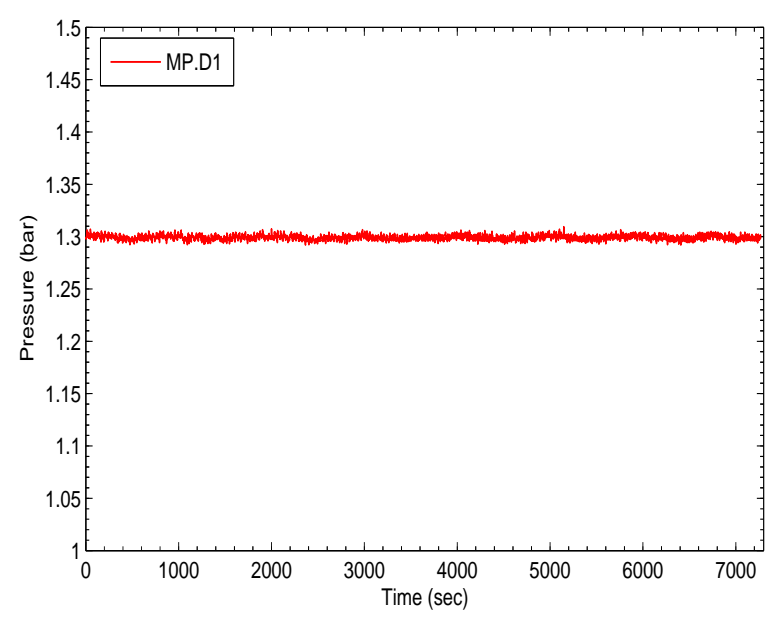

(c) Containment pressure (bar) Nom.val.: 1.3; Mean: 1.299; St.dv.: 0.002

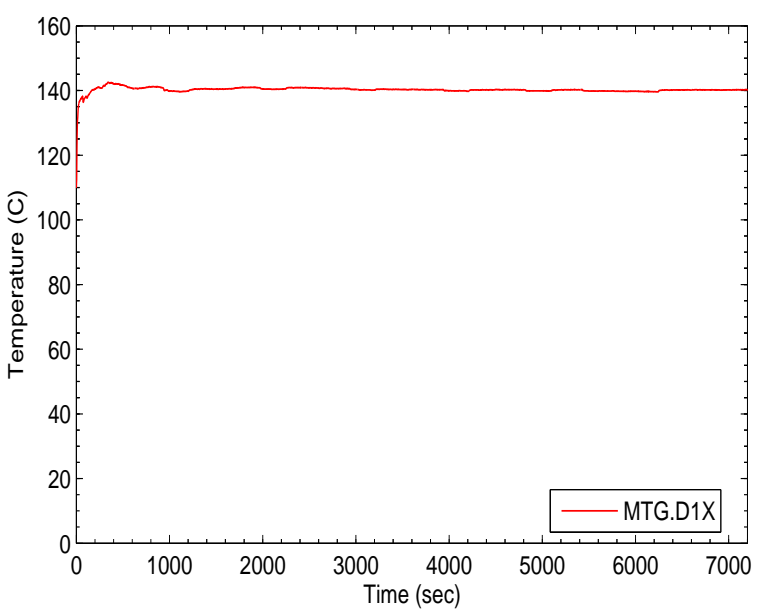

(b) Fluid Injection temperature $\left({ }^{\circ} \mathrm{C}\right)$ Nominal value: 140 ; Mean value: 140.2 ; St.dv.: 1.1

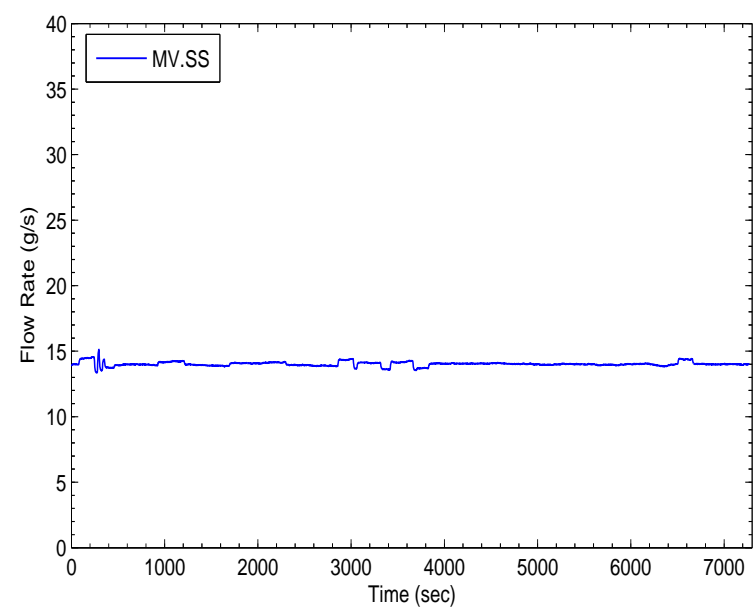

(d) Fluid injection flow rate $(\mathrm{g} / \mathrm{s})$ Nom.val.: 14; Mean: 14.03; St.dv.: 0.16

Figure 6: Initial and boundary conditions for Test 12

Tests 5 and 7 (Figure 8), belonging to the horizontal jet series, were characterized by the same initial Froude numbers but different vent locations. Stratified patterns built up in the early phase of Test 5: the lower part of DW1 remains with a lower content of helium, while in the upper part a nearly uniform increase over the test time period was measured. As Test 5 progressed, the concentration increased also in the lower part of DW1. It should be pointed out that the final concentration reached in DW1 corresponds closely to that of the injected mixture. In Test 7, the steam/helium mixture transported to the vent located at the bottom of DW1 results in a nearly uniform gas concentration over the entire vertical height V1 of DW1.

In DW2, stratified patterns build up with the helium content increasing mainly in the part of the vessel above the IP, where it reaches approximately the same level as in DW1. By comparing the two tests, it can be deduced that the vent location has practically no effect on the helium concentration in DW2 while in DW1 it has an effect during the early phase of the test. During the late phases (profiles at $4200 \mathrm{~s}$ and 6700 s), the vertical profile of helium concentration are comparable (e.g. weak stratification in DW1 and strong stratification in DW2). It should be noted also that gas concentration measurements were also available at different radial locations in both DW1 and DW2 for all the test duration (i.e. not only at the selected locations shown in Figures 7 and 8). 


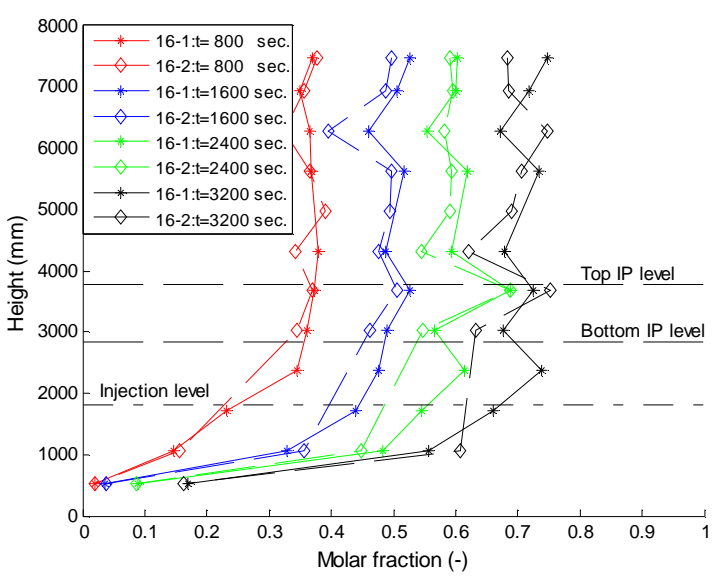

(a) DW1 central axis

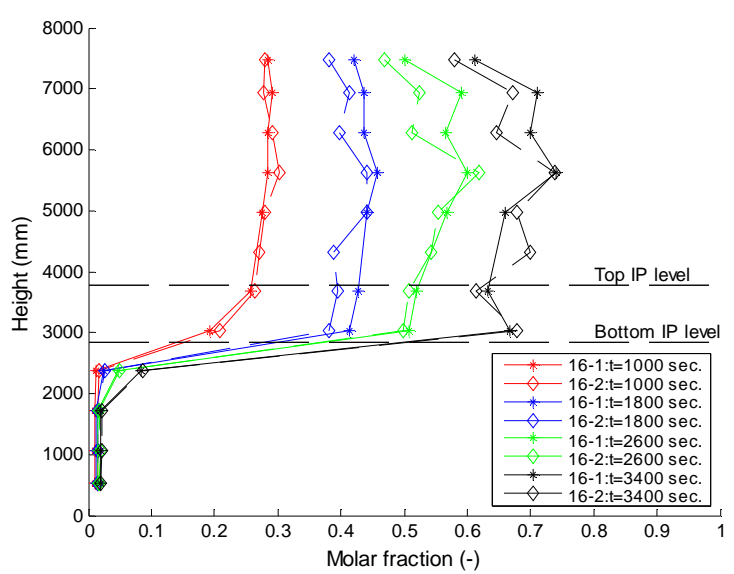

(b) DW2 central axis

Figure 7: Measured steam concentration vertical profiles in DW1 and DW2 (Test 16-1 and 16-2)

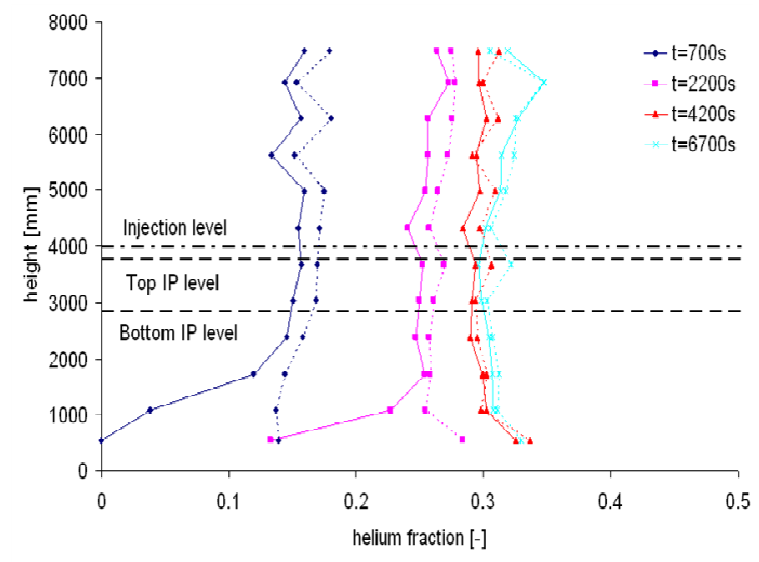

a) DW1 (Test 5 (continuous lines) and Test 7 (dashed lines))

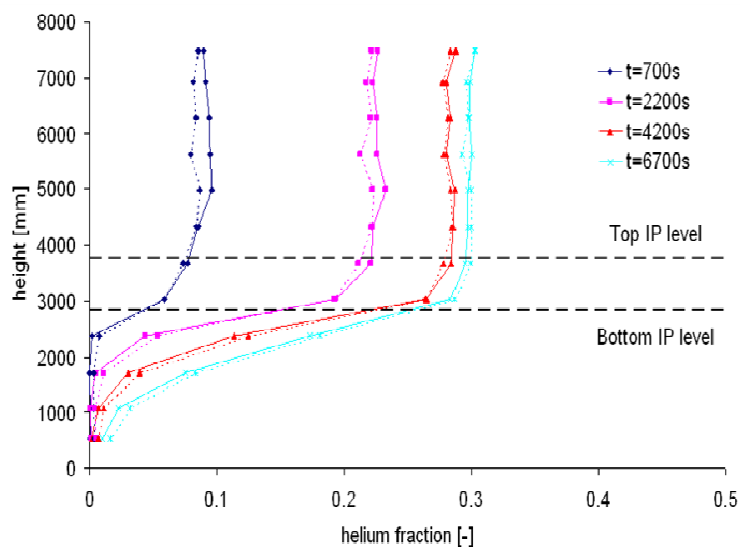

b) DW2 (Test 5 (continuous lines) and Test 7 (dashed lines))

Figure 8: Measured steam concentration vertical profiles in

DW1 and DW2 (Test 5 and 7)

\subsection{Characterization of plume trajectory and flow pattern}

The in-vessel instrumentation allows the trajectory of the plume to be tracked during the entire test. In particular, the flow structure can be inferred from the temperature measurements. For instance, for the low-elevation injection tests, it is recommended to use the information obtained from the dense thermocouple array at the mid-height elevation On that (horizontal plane), $3 \times 13$ thermocouples are mounted on 3 parallel measurement lines. At each time step, instantaneous profiles can thus be obtained. A curve may then be fitted to each of these profiles, and the position of the maximum temperature along the axis estimated. Due to the high measurement density along each profile and to the large enough temperature difference between the centre of the plume and its environment (typically a few ${ }^{\circ} \mathrm{C}$ ), the position of the maxima can be retrieved with reasonable accuracy.

It was always observed that the plume was approximately centered with respect to the axis of the injection, though a slight lateral deviation was observed in some tests. It should be pointed out that in the near-wall plume tests steam was injected into the vessel (DW1) initially filled with air. The steam being lighter than air, rises with positive buoyancy. During the tests, the mixing of steam with air resulted in a decrease of the buoyancy (due to the decrease of ambient density) for the injected steam, and so the plume trajectory became less vertical, i.e. moved towards the center of the vessel.

In Figure 9 (a) is shown an example on how this type of measurement has been used to asses codes with 3D capabilities to infer the plume trajectory (e.g. information on the distance of the plume from the wall, see also Figure 9b). For these simulations, the GOTHIC, CFX-4 and CFX-5 codes have been used, using the standard $\mathrm{k}-\varepsilon$ turbulent model. It can be observed that the radial positions of the maximum temperature 
predicted by GOTHIC are close to the experimental ones (different markers at the same distance from the wall for the experimental data indicate repetition runs for the same test) at the early times selected, and in the range of those predicted by CFX using various meshes (the complete set of results, with all CFD codes used in the benchmark is given by Andreani et al., 2008).

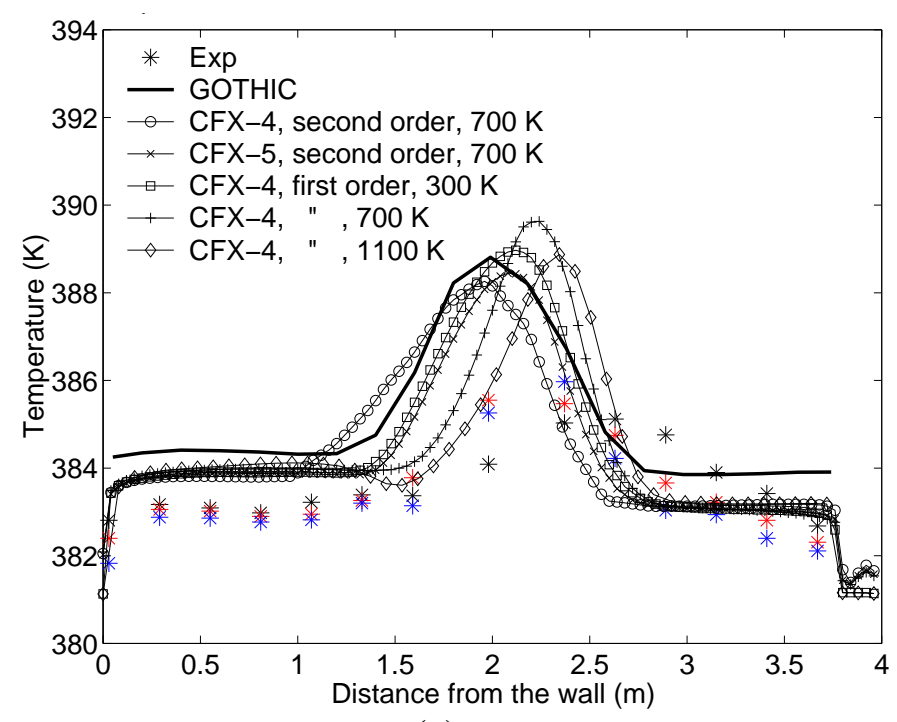

(a)

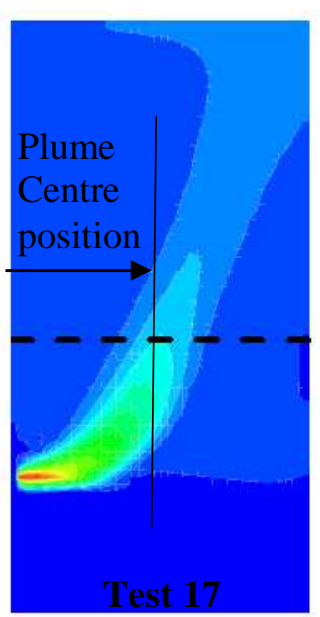

(b)

Figure 9: Radial gas temperature distribution in Vessel 1 at $3.7 \mathrm{~m}$ for Test 17 early in the transient.

\subsection{Three-gas mixture test}

In the three-gas plume Test 25 , the fluid density evolution in the two vessels deriving from the gas injection, transport and steam condensation, controls the flow structures, as well the mixing and stratification. These phenomena are very complex, and include: free-rising plumes, interaction of flow structures, change from a buoyant injection to a negatively buoyant plume in DW1; flow reversals in the IP; changes in the recirculation patterns, multi-layer stratification and stratification erosion in DW2, etc. Among these various physical situations, to illustrate the use of the data collected for code validation purposes, measured data at around $4000 \mathrm{~s}$ are compared with the results obtained using the GOTHIC code in Figure 10. Figure $10 \mathrm{~b}$ ) shows the superimposed gas concentration and velocity fields (calculated with a finer mesh, 24000 cells) in a composite vertical plane which includes the axes of the two vessels and the IP. It can be seen that the upwards propagation of the steam-helium mixture injected in DW1, which initially could rise to the top of the vessel due to its strong buoyancy, is limited by the stable stratification created by the condensation in the dome, and the associated increase in light gas concentration. Countercurrent flow prevails in the IP, driven by small density differences between the two vessels.

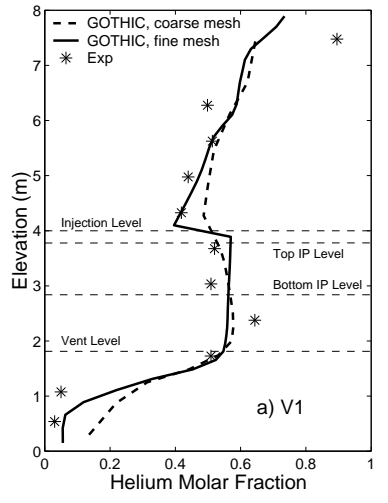

(a)

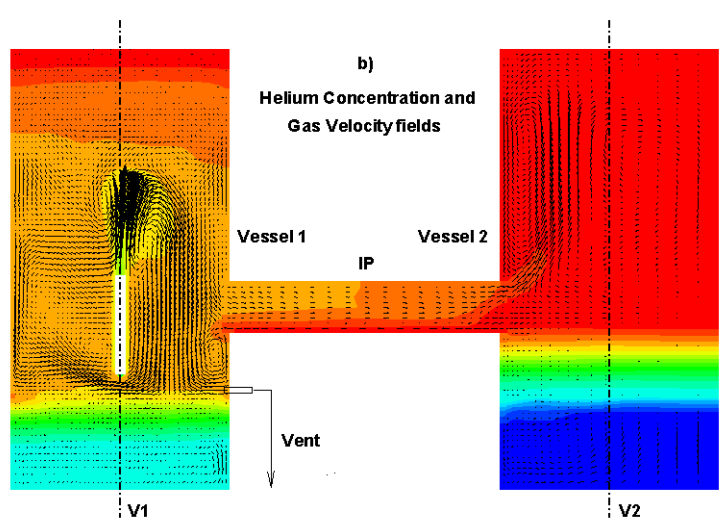

(b)

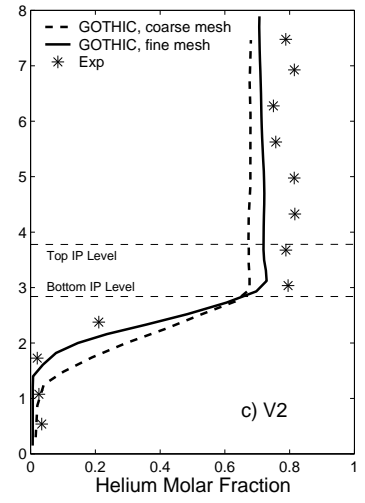

(c)

Figure 10: Comparison between GOTHIC simulation and measured vertical helium distribution in the central axis of two PANDA vessels (a and c) during a SETH test. In (b) is shown the simulation of helium concentration and gas velocity fields. 
The flow pattern in DW2 is characterized by a rising helium-rich plume. Temperature and gas concentration measurements obtained at several locations are consistent with code results. The comparisons between calculated and measured vertical helium distribution in the central axis of the two DWs (i.e. V1 for DW1 and V2 for DW2) are shown in Figures 10 (a) and 10 (c), with a coarse mesh (3500 cells) and a "fine" mesh (24000 cells). The observed discrepancy is thought to be due to too little condensation predicted by the code. In general, the results obtained with GOTHIC for the entire test showed that the prediction of transients characterized by complex evolution of the density difference between compartments is a challenging task, even for a code having 3D capabilities. A more detailed analysis of Test 25 is reported by Paladino et al. (2010c) and Andreani et al. (2010)

\section{CONCLUSIONS}

The OECD SETH PANDA experimental database is suitable to assess the capability of CFD codes to simulate gas mixing and stratification phenomena triggered by plumes and/or jets in multi-compartment geometries. The paper provides some hints on the overall information that can be obtained from the experimental results, and presents examples of the analysis undertaken at PSI using the GOTHIC, CFX-4 and CFX-5 codes.

Characterization of the phenomena, e.g. gas transport, plume trajectories, impinging locations, stratification build-up, condensation, etc., has been possible in the PANDA tests by increasing the number of measurement sensors (especially for gas concentration and temperature). Despite the large number of measurement sensors placed in PANDA, in order to capture precise flow details an optimization of the sensor locations has been necessary by increasing the spatial density distribution of the sensors in specific regions of the vessels. Most of these regions were identified by scoping calculation performed with the GOTHIC code. Near each capillary used for gas concentration measurements a thermocouple (at a typical distance of $3 \mathrm{~mm}$ ) for temperature measurement was also installed. The velocity measurements, which especially when PIV was used, were quite challenging (vessel sizes, seeding, etc,) provides valuable information on 2D flow velocity profiles.

The PANDA facility is currently used in the SETH-2 project (Paladino et al. 2008), (follow-up activity from SETH). In the SETH-2 tests, the initial conditions in the vessels represent a stratified atmosphere, and mixing is obtained by mass (negatively buoyant vertical or horizontal jet, sprays) or energy sources (e.g. energy release by recombiner operation) and sinks (e.g. containment cooler). Although, the SETH-2 tests are not presented in this paper, it should be pointed out that for obtaining CFD-grade data, the instrumentation had to be further upgraded with respect to SETH tests by increasing the number of sensors (and introducing some new type of sensors for measuring low-flow velocities in the IP), and by improving the auxiliary systems for ensuring the specified initial mixture stratification. The SETH and SETH-2 projects provide an important contribution toward the creation of an experimental database for qualifying LWR containment phenomena and providing data for CFD code validation.

\section{Acknowledgments}

The authors gratefully acknowledge the support of all the countries, and in particular the international organizations, participating in the OECD/SETH project. The authors would like to thank all the members of the Management Board and the Programme Review Group of the SETH project for their help in defining the test programme and evaluating the test results. Also, all the current and former PSI staff involved in the SETH PANDA tests are acknowledged.

\section{REFERENCES}

Andreani, M., Haller, K., Heitsch, M., Hemström, B., Karppinen, I., Macek, J., Schmid, J., Paillere, H., Toth, I. 2008. A Benchmark Exercise on the use of CFD Codes for Containment Issues using Best Practice Guidelines: A Computational Challenge. Nucl. Eng. Des. 238, 502-516.

M. Andreani, D. Paladino and T. George, "Simulation of basic gas mixing tests with condensation in the PANDA facility using the GOTHIC code", Nuclear Engineering and Design doi:10.1016/j.nucengdes.2010.02.021 (2010).

M. Andreani and D. Paladino, "Simulation of gas mixing and transport in a multi-compartment geometry using the GOTHIC containment code and relatively coarse mesh", Nuclear Engineering and Design, doi:10.1016/j.nucengdes.2010.02.020 (2010). 
O. Auban, R. Zboray and D. Paladino, "Investigation of large-scale gas mixing and stratification phenomena related to LWR containment studies in the PANDA facility", Nuclear Engineering and Design 237 (2007) 409-419.

A. Bentaib (IRSN), A. Bleyer S. Schwarz et al. "ASTEC validation on PANDA SETH", In: Proceeding of the 13th International Topical Meeting on Nuclear Reactor Thermal Hydraulics (NURETH13), Kanazawa City, Ishikawa Prefecture, Japan, September 27-October 2, 2009

J. Dreier, D. Paladino, M. Huggenberger, M. Andreani, G. Yadigaroglu, 2008. PANDA: a Large Scale Multi-Purpose, Test Facility for LWR Safety Research, In: Proceedings of the International Conference on the Physics of Reactors (PHYSOR08), Interlaken, Switzerland.

OECD, "OECD/CSNI Workshop on Advanced Thermal-hydraulics and Neutronic Codes: Current Status and Future Applications", Barcelona, Codes 2000, Spain, 10-13 April (2000).

OECD/SETH Seminar 2007, Institut de Radioprotection et de surete Nucleaire, Fontenay-Aux-Roses cedex, France, June 18-19, 2007.

D. Paladino, M. Huggenberger, M. Andreani, S. Gupta, S. Guentay, J. Dreier, H. Prasser, "LWR Containment safety research in PANDA", International Congress on Advances in Power Plants (ICAPP 08)-Anaheim, CA USA, June -12, 2008.

D. Paladino, R. Zboray and O. Auban, "The PANDA Tests 9 and 9bis investigating gas mixing and stratification triggered by low momentum plumes", Nuclear Engineering and Design, 240, 1262-1270 (2010a)

D. Paladino, R. Zboray, M. Andreani and J. Dreier, "Flow transport and mixing induced by horizontaljets impinging on a vertical wall of the multi-compartment PANDA facility", Nuclear Engineering and Design, doi: 10.1016/j.nucengdes.2010.03.036. (2010b)

D. Paladino, R. Zboray, P. Benz and M. Andreani, "Three-gas-mixture plume inducing mixing and stratification in a multi-compartment containment", Nuclear Engineering, Vol. 240, Issue 2, pp. 210-220 (2010c).

P. Royl, J. R. Travis, W. Breitung, "GASFLOW Validation with Steam/Helium Distribution in a Multi Room Test Facility (PANDA SETH test 25), In: Proceeding of the Annual Meeting on nuclear Technology, Hamburg, Germany May 27-29, 2008.

P. Royl, K. Jongtae, K. Sang-Baik, "GASFLOW Validation with PANDA Tests from the OECD SETH Benchmark covering steam/air and steam(helium/air mixtures", Science and Technology of Nuclear Installations, Volume 2009 (2009), Article ID 759878, 13 pagesdoi:10.1155/2009/759878

B. Smith, "Identification and prioritization of generic nuclear safety problems requiring CFD analysis", In: Proc. of the $17^{\text {th }}$ Int. Conf. on Nuc. Eng. ICONE17, Brussels, Belgium July 12-16, (2009).

G. Yadigaroglu, M. Andreani, J. Dreier, P. Coddington, "Trends and needs in experimentation and numerical simulation for LWR safety”, Nuclear Engineering and Design, 221, 205-223 (2003).

R. Zboray and D. Paladino, "Experiments on basic thermalhydraulic phenomena relevant for LWRContainments: gas mixing and transport induced by buoyant jets in a multi-compartment geometry", Nuclear Engineering and Design (in press), (2010). 